\title{
An International Survey on Noninvasive Ventilation Use for Acute Respiratory Failure in General Non-Monitored Wards
}

\author{
Luca Cabrini MD, Antonio Esquinas MD, Laura Pasin MD, Pasquale Nardelli MD, \\ Elena Frati MD, Margherita Pintaudi MD, Paulo Matos MD, \\ Giovanni Landoni MD, and Alberto Zangrillo MD
}

\begin{abstract}
BACKGROUND: Use of noninvasive ventilation (NIV) for the treatment of patients with acute respiratory failure (ARF) has greatly increased in the last decades. In contrast, the increasing knowledge of its effectiveness and physician confidence in managing this technique have been accompanied by a declining number of available ICU beds. As a consequence, the application of NIV outside the ICU has been reported as a growing phenomenon. Previously published surveys highlighted a great heterogeneity in NIV use, clinical indications, settings, and efficacy. Moreover, they revealed a marked heterogeneity with regard to staff training and technical and organizational aspects. We performed the first worldwide web-based survey focused on NIV use in general wards for ARF. METHODS: A questionnaire to obtain data regarding hospital and ICU characteristics, settings and modalities of NIV application and monitoring, estimated outcomes, technical and organizational aspects, and observed complications was developed. The multiple-choice anonymous questionnaire to be filled out online was distributed worldwide by mail, LinkedIn, and Facebook professional groups. RESULTS: One-hundred fifty-seven questionnaires were filled out and analyzed. Respondents were from 51 countries from all 5 continents. NIV application in general wards was reported by $66 \%$ of respondents. Treatments were reported as increasing in $57 \%$ of cases. Limited training and human resources were the most common reasons for not using NIV in general wards. Overall, most respondents perceived that NIV avoids tracheal intubation in most cases; worsening of ARF, intolerance, and inability to manage secretions were the most commonly reported causes of NIV failure. CONCLUSIONS: Use of NIV in general wards was reported as effective, common, and gradually increasing. Improvement in staff training and introduction of protocols could help to make this technique safer and more common when applied in general wards setting. Key words: noninvasive ventilation; survey; general wards; acute respiratory failure. [Respir Care 2015;60(4):586-592. (C) 2015 Daedalus Enterprises]
\end{abstract}

\section{Introduction}

The use of noninvasive ventilation (NIV) for the treatment of patients with acute respiratory failure (ARF) has

Drs Cabrini, Pasin, Nardelli, Frati, Pintaudi, Landoni, and Zangrillo are affiliated with the Department of Anesthesia and Intensive Care, Istituto di Ricovero e Cura a Carattere Scientifico, San Raffaele Scientific Institute, Milan, Italy. Dr Esquinas is affiliated with the Intensive Care Unit, Hospital Morales Meseguer, Murcia, Spain. Dr Matos is affiliated with the Pneumology Department, Coimbra Hospital and University, Coimbra, Portugal.

Supplementary material related to this paper is available at http://www. rcjournal.com. greatly increased in the last decades. ${ }^{1}$ Early treatment with NIV is of crucial importance to improve a patient's outcome because it has been demonstrated to reduce the need for tracheal intubation, ICU stay, and re-intubation rates in different patient groups. ${ }^{2-4}$ However, the increasing aware-

\footnotetext{
The authors have disclosed no conflicts of interest.

Correspondence: Laura Pasin MD, Department of Anesthesia and Intensive Care, Istituto di Ricovero e Cura a Carattere Scientifico, San Raffaele Scientific Institute, Via Olgettina 60, 20132 Milan, Italy. E-mail: pasin.laura@hsr.it.
}

DOI: $10.4187 /$ respcare.03593 
ness of the effectiveness of NIV has been accompanied, worldwide, by a declining number of available ICU beds over the years. This shortage, together with an increased confidence of physicians in managing this technique, has resulted in the increased use of NIV outside the ICU. Preliminary reports confirmed NIV efficacy even in a general ward setting. ${ }^{5}$ Previously published surveys performed on this topic highlighted a great heterogeneity in NIV use, clinical indications, settings, and efficacy in general wards. ${ }^{6-16}$ Moreover, they revealed a marked heterogeneity even with regard to staff training and technical and organizational aspects of NIV use. We therefore performed the first worldwide web-based international survey focused on NIV use in general wards for ARF.

\section{Methods}

We developed a questionnaire to obtain data regarding hospital, general ward (outside ICU, non-monitored ward) or respiratory intermediate unit (characterized by a nurse/patient ratio of 1:3-1:4, multivariable monitors, NIV or invasive ventilation allowed, immediate availability of a physician) ${ }^{17}$; ICU characteristics, settings, and modalities of NIV application and monitoring; perceived outcomes; technical and organizational aspects; and observed complications. The questionnaire was evaluated for clarity and relevance by an international panel of NIV experts (see the supplementary materials at http://www.rcjournal.com). In October 2013, the multiple-choice questionnaire was sent by mail (using all the pertinent mailing lists available to us), LinkedIn, and Facebook professional groups via a link to Maian Survey, a free online survey system. The questionnaire was anonymous, and the collected answers were automatically tabulated in a web Excel worksheet.

\section{Results}

One-hundred fifty-seven questionnaires were filled out online and analyzed. Respondents were from 51 countries (Table 1).

The characteristics of the respondents' hospitals are listed in Table 2. In 66\% of the hospitals, NIV was applied in general wards. Limited training and limited human resources were the most common reported reasons from centers not using NIV in general wards; very few respondents reported doubts of its efficacy.

In $57 \%$ of cases, NIV treatment in general wards was reported as increasing. Training had been performed before NIV introduction in general wards in $49 \%$ of cases; periodic education was available in $58 \%$ of the centers. In

\section{QUICK LOOK}

\section{Current knowledge}

The use of noninvasive ventilation (NIV) for the treatment of exacerbations of COPD has increased markedly over the last decade owing to growing evidence demonstrating improved outcomes. Growth of NIV outside of intensive care has been variable based on indication and geography.

\section{What this paper contributes to our knowledge}

A worldwide survey of NIV suggests that use outside the ICU is increasing. The survey identified lack of training and protocols as impediments to safe and effective use on the general floor.

$61 \%$ of the centers, once started on NIV, the patient was always or often left in the initial ward, whereas only $19 \%$ of respondents never left the patients on NIV in an general ward.

The ventilators commonly belonged to the ICU or the pulmonology ward, whereas in only $4 \%$ of cases, every ward had its own devices. A trend toward an increase in the number of CPAP/NIV devices was reported by $59 \%$ of respondents.

Treatments were often not protocolized (see Table 2). Pulmonologists and intensivists prescribed NIV in most hospitals; however, in $29 \%$ of cases, ward physicians could prescribe NIV autonomously. In $32 \%$ of hospitals, the physician authorized to prescribe NIV was not continuously present; accordingly, the nursing staff and ward physician had a relevant role in the management of NIV, as reported by two thirds of respondents.

Treated diseases and monitoring aspects are summarized in Tables 3 and 4. In Table 5, the most common complications are reported. Overall, most respondents perceived that NIV was successful in most cases (Table 6); worsening of ARF, intolerance to the interface, and inability to manage secretions were the most commonly reported causes of NIV failure (Table 7).

\section{Discussion}

This study is the first international survey focusing on NIV for ARF in general non-monitored wards. The limited number of respondents compared with the huge number of hospitals in the world makes our data preliminary: our results should not be generalized or considered representative of all hospitals worldwide. This bias limits also the 
Table 1. Location of Respondents' Hospitals

\begin{tabular}{|c|c|c|c|}
\hline $\begin{array}{l}\text { Region and } \\
\text { Country }\end{array}$ & $\begin{array}{l}\text { No. of } \\
\text { Hospitals }\end{array}$ & $\begin{array}{c}\text { Percentage } \\
\text { Overall }\end{array}$ & $\begin{array}{l}\text { Percentage } \\
\text { of Region }\end{array}$ \\
\hline Total & 157 & & \\
\hline Europe & 84 & 53.5 & \\
\hline Italy & 19 & 12.1 & 22.6 \\
\hline France & 10 & 6.4 & 11.9 \\
\hline Germany & 10 & 6.4 & 11.9 \\
\hline Portugal & 9 & 5.7 & 10.7 \\
\hline Spain & 7 & 4.5 & 8.3 \\
\hline United Kingdom & 4 & 2.5 & 4.8 \\
\hline Finland & 2 & 1.3 & 2.4 \\
\hline Ireland & 2 & 1.3 & 2.4 \\
\hline Norway & 2 & 1.3 & 2.4 \\
\hline Romania & 2 & 1.3 & 2.4 \\
\hline Russia & 2 & 1.3 & 2.4 \\
\hline Slovakia & 2 & 1.3 & 2.4 \\
\hline The Netherlands & 2 & 1.3 & 2.4 \\
\hline Austria & 1 & 0.6 & 1.2 \\
\hline Belgium & 1 & 0.6 & 1.2 \\
\hline Bulgaria & 1 & 0.6 & 1.2 \\
\hline Croatia & 1 & 0.6 & 1.2 \\
\hline Denmark & 1 & 0.6 & 1.2 \\
\hline Hungary & 1 & 0.6 & 1.2 \\
\hline Iceland & 1 & 0.6 & 1.2 \\
\hline Macedonia & 1 & 0.6 & 1.2 \\
\hline Monaco & 1 & 0.6 & 1.2 \\
\hline Poland & 1 & 0.6 & 1.2 \\
\hline Serbia & 1 & 0.6 & 1.2 \\
\hline Asia & 31 & 19.8 & \\
\hline India & 10 & 6.4 & 32.3 \\
\hline Turkey & 5 & 3.2 & 16.1 \\
\hline Pakistan & 3 & 1.9 & 9.7 \\
\hline Saudi Arabia & 2 & 1.3 & 6.5 \\
\hline Taiwan & 2 & 1.3 & 6.5 \\
\hline United Arab Emirates & 2 & 1.3 & 6.5 \\
\hline China & 1 & 0.6 & 3.2 \\
\hline Iraq & 1 & 0.6 & 3.2 \\
\hline Japan & 1 & 0.6 & 3.2 \\
\hline Jordan & 1 & 0.6 & 3.2 \\
\hline Kuwait & 1 & 0.6 & 3.2 \\
\hline Central and South America & 13 & 8.3 & \\
\hline Brazil & 5 & 3.2 & 38.5 \\
\hline Argentina & 2 & 1.3 & 15.4 \\
\hline Peru & 2 & 1.3 & 15.4 \\
\hline Colombia & 1 & 0.6 & 7.7 \\
\hline Costa Rica & 1 & 0.6 & 7.7 \\
\hline Ecuador & 1 & 0.6 & 7.7 \\
\hline Venezuela & 1 & 0.6 & 7.7 \\
\hline North America & 9 & 5.8 & \\
\hline United States & 5 & 3.2 & 55.6 \\
\hline Canada & 2 & 1.3 & 22.2 \\
\hline Mexico & 2 & 1.3 & 22.2 \\
\hline Oceania & 5 & 3.2 & \\
\hline Australia & 3 & 1.9 & 60.0 \\
\hline New Zealand & 2 & 1.3 & 40.0 \\
\hline Africa & 4 & 2.4 & \\
\hline Egypt & 1 & 0.6 & 25.0 \\
\hline Lebanon & 1 & 0.6 & 25.0 \\
\hline Morocco & 1 & 0.6 & 25.0 \\
\hline Tunisia & 1 & 0.6 & 25.0 \\
\hline Unidentified & 11 & 7.0 & \\
\hline
\end{tabular}

Table 2. Characteristics of the Respondents' Hospitals and Settings of NIV Use

\begin{tabular}{|c|c|}
\hline Characteristics & $\begin{array}{l}\text { Values, } n \\
\quad(\%)\end{array}$ \\
\hline \multicolumn{2}{|l|}{ Hospital type } \\
\hline Academic & $110(69.1)$ \\
\hline Non-academic & $47(30.9)$ \\
\hline \multicolumn{2}{|l|}{ No. of hospital beds } \\
\hline$<500$ & $64(40.8)$ \\
\hline $500-1,000$ & $53(33.8)$ \\
\hline$>1,000$ & $40(25.4)$ \\
\hline \multicolumn{2}{|c|}{$\begin{array}{l}\text { Presence of a respiratory step-down unit (also defined } \\
\text { as a high-dependency or intermediate unit) }\end{array}$} \\
\hline Yes & $76(48.8)$ \\
\hline No & $81(51.2)$ \\
\hline \multicolumn{2}{|c|}{$\begin{array}{l}\text { NIV applied in the respiratory step-down unit, if } \\
\text { present }\end{array}$} \\
\hline Yes & $83(53.1)$ \\
\hline No & $12(7.5)$ \\
\hline Not present & $62(39.4)$ \\
\hline \multicolumn{2}{|l|}{ NIV applied in the ICU, if present } \\
\hline Yes & $146(93.1)$ \\
\hline No & $6(3.8)$ \\
\hline Not present & $5(3.1)$ \\
\hline \multicolumn{2}{|c|}{ NIV applied in the emergency department, if present } \\
\hline Yes & $114(73.0)$ \\
\hline No & $25(15.7)$ \\
\hline Not present & $18(11.3)$ \\
\hline \multicolumn{2}{|l|}{ NIV applied in general wards } \\
\hline Yes & $104(66.0)$ \\
\hline No & $53(34.0)$ \\
\hline \multicolumn{2}{|l|}{ Reasons for not using NIV in general wards } \\
\hline Safety concerns & $32(20.4)$ \\
\hline Lack of training & $46(29.9)$ \\
\hline Limited human resources (understaffed) & $39(24.8)$ \\
\hline Limited financial resources & $26(16.6)$ \\
\hline Doubts about NIV efficacy & $6(3.8)$ \\
\hline Other & $16(10.2)$ \\
\hline \multicolumn{2}{|c|}{ No. of NIV treatments in general wards increasing } \\
\hline Yes & $90(57.3)$ \\
\hline No & $49(31.2)$ \\
\hline Unknown & $18(11.5)$ \\
\hline \multicolumn{2}{|c|}{$\begin{array}{l}\text { Specific training provided before introducing NIV in } \\
\text { general wards }\end{array}$} \\
\hline Yes & $79(50.6)$ \\
\hline No & $78(49.4)$ \\
\hline \multicolumn{2}{|l|}{ NIV use in general wards } \\
\hline Every hospital ward & $49(31.5)$ \\
\hline Only in some hospital wards & $108(68.5)$ \\
\hline \multicolumn{2}{|c|}{ Patient left in the general ward after starting NIV } \\
\hline Always & $31(19.6)$ \\
\hline Often & $71(45.3)$ \\
\hline Rarely & $35(22.3)$ \\
\hline \multirow[t]{2}{*}{ Never } & $20(12.8)$ \\
\hline & (continued) \\
\hline
\end{tabular}


Table 2. Continued

\begin{tabular}{|c|c|}
\hline Characteristics & $\begin{array}{c}\text { Values, } n \\
(\%)\end{array}$ \\
\hline \multicolumn{2}{|l|}{ NIV modalities used in general wards } \\
\hline CPAP & $88(56.1)$ \\
\hline Bi-level or pressure support & $119(75.8)$ \\
\hline Pressure control & $30(19.1)$ \\
\hline Volume control & $22(14.0)$ \\
\hline Other & $14(8.9)$ \\
\hline \multicolumn{2}{|l|}{ No. of CPAP devices available in the hospital } \\
\hline 1 & $4(2.7)$ \\
\hline 2 & $7(4.7)$ \\
\hline 3 & $15(9.4)$ \\
\hline 4 & $16(10.1)$ \\
\hline 5 & $11(6.7)$ \\
\hline$>5$ & $104(66.4)$ \\
\hline \multicolumn{2}{|l|}{$\begin{array}{l}\text { No. of ventilators available in the hospital for } \\
\text { pressure support/BPAP/volume control } \\
\text { ventilation }\end{array}$} \\
\hline 1 & $1(0.6)$ \\
\hline 2 & $7(4.5)$ \\
\hline 3 & $5(3.2)$ \\
\hline 4 & $12(7.7)$ \\
\hline 5 & $8(5.1)$ \\
\hline$>5$ & $124(78.8)$ \\
\hline \multicolumn{2}{|l|}{ Ventilator owner } \\
\hline ICU & $112(71.3)$ \\
\hline Emergency department & $57(36.3)$ \\
\hline Pulmonology & $83(52.9)$ \\
\hline Every ward has its own ventilators & $12(7.6)$ \\
\hline Other & $24(15.3)$ \\
\hline \multicolumn{2}{|l|}{ Interface used for NIV } \\
\hline Oronasal masks & $143(91.1)$ \\
\hline Nasal masks & $73(46.5)$ \\
\hline Helmets & $34(21.7)$ \\
\hline Other & $24(15.3)$ \\
\hline \multicolumn{2}{|l|}{ Availability of different size and models } \\
\hline Yes & $148(94.2)$ \\
\hline No & $9(5.8)$ \\
\hline \multicolumn{2}{|l|}{ Presence of NIV-dedicated protocol for: } \\
\hline Indications & $81(51.5)$ \\
\hline Treatment modalities & $60(38.2)$ \\
\hline Weaning for NIV & $50(31.8)$ \\
\hline Monitoring & $69(43.9)$ \\
\hline Absolute and relative contraindications & $65(41.4)$ \\
\hline No protocol is present & $66(42.0)$ \\
\hline \multicolumn{2}{|l|}{ NIV prescriber in general wards } \\
\hline Ward physician & $46(29.3)$ \\
\hline Pulmonologist & $108(68.8)$ \\
\hline Anesthesiologist & $55(35.0)$ \\
\hline Emergency physician & $52(33.1)$ \\
\hline Intensivist & $83(52.9)$ \\
\hline Medical emergency team/rapid response team & $23(14.6)$ \\
\hline Respiratory therapist & $24(15.3)$ \\
\hline Other & $\begin{array}{c}6(3.8) \\
\text { (continued) }\end{array}$ \\
\hline
\end{tabular}

Table 2. Continued

\begin{tabular}{lc}
\hline \hline \multicolumn{1}{c}{ Characteristics } & $\begin{array}{c}\text { Values, } n \\
(\%)\end{array}$ \\
\hline Is the specialist authorized to prescribe NIV & \\
$\quad$ always present in the hospital? & $107(68.0)$ \\
Yes & $50(32.0)$ \\
No & $57(36.6)$ \\
Protocol to manage NIV failure & $64(40.5)$ \\
Yes & $36(22.9)$ \\
No & \\
Depends mainly on ICU bed availability & \\
Role of general ward physicians in days following & $58(36.6)$ \\
$\quad$ NIV initiation & $31(19.9)$ \\
Manage every aspect of the treatment & $68(43.5)$ \\
No role in NIV & \\
Manage NIV in conjunction with the physician \\
$\quad$ who prescribed it \\
Role of general ward nurses in days following \\
$\quad$ NIV initiation \\
Manage every aspect of the treatment \\
No role in NIV \\
Manage NIV in conjunction with the ward \\
$\quad$ physician and physician who prescribed it \\
Presence of a respiratory therapist in general \\
$\quad$ wards using NIV \\
Yes, in all wards \\
Yes, in most wards \\
Yes, but only in a few wards \\
No \\
\hline NIV = noninvasive ventilation \\
BPAP = bi-level positive airway pressure \\
$\quad 89(56.9)$ \\
\end{tabular}

value of comparisons with other surveys. Nevertheless, our original results offer a basis for future larger studies.

The results from our study, including respondents from all 5 continents, suggests that NIV use in general wards is common and growing worldwide. In a recent survey among the members of the Noninvasive Ventilatory Support Group of the European Respiratory Society, NIV use in general (mainly pulmonary) wards was reported as common. ${ }^{16}$ The percentage of hospitals using NIV in general wards is increasing: from $<10 \%$ in $2005^{9}$ to $66 \%$ in our survey. As reported in previous studies, ${ }^{6,7,9}$ in most hospitals, NIV is prescribed only in some hospital wards, and once the treatment is started, patients generally remain in their wards. The main reason for this phenomenon is likely the overall respondents' perception of NIV efficacy. In fact, $>50 \%$ of respondents believed that NIV was successful in more than half of cases. This percentage is doubled compared with the percentages reported in previous surveys. ${ }^{6,7} \mathrm{Nev}-$ ertheless, the perceived success rate is still lower than the success rates reported in most published studies on NIV4: NIV efficacy in general wards should be further improved, and simple interventions to achieve this aim seem at hand. 
Table 3. Causes of ARF Treated by NIV Outside the ICU

\begin{tabular}{lc}
\hline \hline \multicolumn{1}{c}{ Cause of ARF } & $\begin{array}{c}\text { Hospitals Using NIV } \\
\text { Outside the ICU for } \\
\text { This Cause of ARF (\%) }\end{array}$ \\
\hline COPD exacerbation & 94.3 \\
Acute pulmonary edema & 85.4 \\
Neuromuscular diseases & 77.1 \\
Postoperative ARF & 72.0 \\
Pneumonia in immunocompromised & 63.0 \\
patients & \\
Palliation & 51.0 \\
Pneumonia in non-immunocompromised & 41.4 \\
$\quad$ patients & 34.4 \\
Asthma & 26.1 \\
Thoracic trauma & \\
& \\
ARF $=$ acute respiratory failure & \\
NIV = noninvasive ventilation & \\
\hline
\end{tabular}

Table 4. Reported Standard Monitoring for NIV Treatments Outside the ICU

\begin{tabular}{lc}
\hline \hline \multicolumn{1}{c}{ Monitoring } & $\begin{array}{c}\text { Hospitals Routinely } \\
\text { Using NIV (\%) }\end{array}$ \\
\hline Continuous pulse oximetry & 80.3 \\
Arterial blood gas analysis when clinically & 68.8 \\
$\quad$ required & 44.6 \\
Visits by the specialist prescribing NIV more & \\
$\quad$ than once daily & 43.9 \\
Continuous electrocardiogram & 39.5 \\
Arterial blood gas analysis at fixed times & 52.2 \\
Continuous noninvasive arterial blood pressure & 16.6 \\
Daily visit by the specialist prescribing NIV & 12.1 \\
No standard & \\
NIV = noninvasive ventilation & \\
\hline
\end{tabular}

As an example, nearly $42 \%$ of respondents attributed NIV failure to poor patient compliance with the interface: a careful, better choice and management of the most comfortable interface could likely be obtained through better staff training.

In addition to well-established indications such as acute pulmonary edema and COPD exacerbation, NIV is also commonly used in conditions in which response to NIV is less clear, such as asthma. Moreover, use for indications with a known high failure rate, such as pneumonia, in non-immunocompromised patients has been reported. These results are comparable with those reported by Cabrini et al $^{6}$ in 2011, with the exception of neuromuscular diseases, which was a much more prevalent cause for NIV use outside the ICU in our survey $(77 \%$ vs $38 \%)$.
Table 5. Complications or Problems Reported in Patients Receiving NIV

\begin{tabular}{lc}
\hline \hline \multicolumn{1}{c}{ Complication or Problem } & $\begin{array}{c}\text { Respondents Reporting a } \\
\text { Complication or Problem (\%) }\end{array}$ \\
\hline Skin lesions due to mask & 72.0 \\
Excessive agitation of patient & 67.5 \\
Excessive air losses around a mask & 65.6 \\
Patient's refusal of or insufficient & 67.5 \\
$\quad$ compliance with NIV & \\
Insufficient ward doctor cooperation & 28.0 \\
Insufficient ward nurse cooperation & 26.8 \\
Sudden arterial desaturation & 19.7 \\
Ventilator malfunctioning & 19.1 \\
Coma & 7.0 \\
Delay in tracheal intubation in the & 25.5 \\
$\quad$ case of NIV failure & \\
Other & 5.7 \\
Conjunctivitis & 15.9 \\
Delay of visit by the specialist & 15.3 \\
prescribing NIV when summoned & \\
\hline NIV = noninvasive ventilation & \\
\hline
\end{tabular}

Table 6. Perceived NIV Success Rate in General Wards

\begin{tabular}{lc}
\hline \hline $\begin{array}{c}\text { Overall Average NIV Success Rate in } \\
\text { General Wards (Avoidance of Tracheal } \\
\text { Intubation and Admission to ICU) }\end{array}$ & $\begin{array}{c}\text { Respondents Reporting } \\
\text { NIV Success Rate in } \\
\text { General Wards (\%) }\end{array}$ \\
\hline$<25 \%$ & 11.6 \\
$25-49 \%$ & 22.6 \\
$50-74 \%$ & 25.3 \\
$>75 \%$ & 26.0 \\
Unknown & 14.4 \\
& \\
\hline NIV = noninvasive ventilation & \\
\hline
\end{tabular}

Table 7. Causes of NIV Failure in General Wards

\begin{tabular}{lc}
\hline \hline \multicolumn{1}{c}{$\begin{array}{c}\text { Most Common Cause of NIV } \\
\text { Failure in General Wards }\end{array}$} & $\begin{array}{c}\text { Respondents Reporting } \\
\text { the Most Common Cause (\%) }\end{array}$ \\
\hline Worsening respiratory failure & 67.5 \\
Inability to manage secretions & 38.9 \\
Intolerance to the interface & 42.0 \\
Deteriorating level of consciousness & 28.0 \\
NIV-related complications & 17.2 \\
Other & 9.6 \\
& \\
\hline NIV = noninvasive ventilation & \\
\hline
\end{tabular}

In general, NIV should not be used in general wards when its efficacy is uncertain, at a minimum, and better monitored settings are preferred. However, the reported data do not necessarily imply that there is a lack of awareness about NIV failure risk; on the contrary, they could 
merely demonstrate that better monitored beds are often unavailable, forcing physicians to manage ARF in suboptimal settings. Nevertheless, awareness of NIV limitations and risks should be promoted: mandatory preliminary training and the use of a protocol could be of help if NIV is to be administered in non-monitored wards.

Finally, lack of training and limited human and financial resources (not monitored wards) are the most common reported reasons for not using NIV in general. Despite the increasing data on NIV efficacy, in particular when applied early, ${ }^{2}$ a relevant percentage of hospitals have not yet decided to invest in this field. It is worth noting that the cost effectiveness of NIV outside the ICU has already been demonstrated. ${ }^{18,19}$

NIV use in general wards is an area of research that has been largely neglected compared with studies performed in ICUs. The fact that almost all published studies on NIV were performed in ICUs could be misleading, as the results might not accurately represent where NIV is currently used in the real world. Our study suggests that research on NIV use outside the ICU is urgently required.

\section{Limitations}

Our survey has some limitations. We (experienced in both NIV and surveys) developed the questionnaire, and it was reviewed by a larger number of international experts; however, the questionnaire did not undergo a full evaluation process. Information about the criteria used to define respiratory failure in every center and the severity of the respiratory failure was not collected: future surveys should consider these issues to better understand which patients are currently treated on general wards. Data on NIV performed in general wards on do-not-intubate patients or patients considered unfit for ICU admission (or who refused intubation or ICU admission) were not collected; these data would have been of help in better evaluating the use of NIV for controversial indications, such as asthma and pneumonia, in general wards. The hospitals that agreed to participate in the survey are not representative of all hospitals worldwide. Therefore, comparisons with previous studies should be made with caution. Moreover, the number of respondents was rather limited. Because the questionnaire was distributed by social media, we do not know how many people were contacted; for the same reason, we cannot report the responding rate among the different countries or different types of hospitals. However, the aim of the survey was to offer a first look at NIV use outside the ICU. We consider our effort successful, as hospitals from all 5 continents returned the questionnaire. We did not collect data on the profession or specialization of the respondents; respondents could report different complementary data or perceptions about NIV use. Finally, we explored a limited number of NIV aspects: future surveys should focus on specific aspect such as protocols, organization, association between NIV use on general wards and shortage of ICU beds, and physicians' preferences.

\section{Conclusions}

Based on this first international survey, NIV is often applied in general wards, and its use is increasing. Criticalities such as lack of training and protocols are reported and should be addressed to make NIV use safer and more effective. Further research in this area is required.

\section{REFERENCES}

1. Schnell D, Timsit JF, Darmon M, Vesin A, Goldgran-Toledano D, Dumenil AS, et al. Noninvasive mechanical ventilation in acute respiratory failure: trends in use and outcomes. Intensive Care Med 2014;40(4):582-591.

2. Nava S, Hill N. Non-invasive ventilation in acute respiratory failure. Lancet 2009;374(9685):250-259.

3. Antonelli M, Conti G, Rocco M, Bufi M, De Blasi RA, Vivino G, et al. A comparison of noninvasive positive-pressure ventilation and conventional mechanical ventilation in patients with acute respiratory failure. N Engl J Med 1998;339(7):429-435.

4. Glossop AJ, Shephard N, Bryden DC, Mills GH. Non-invasive ventilation for weaning, avoiding reintubation after extubation and in the postoperative period: a meta-analysis. Br J Anaesth 2012;109(3):305314.

5. Cabrini L, Idone C, Colombo S, Monti G, Bergonzi PC, Landoni G, et al. Medical emergency team and non-invasive ventilation outside ICU for acute respiratory failure. Intensive Care Med 2009;35(2): 339-343.

6. Cabrini L, Antonelli M, Savoia G, Landriscina M. Non-invasive ventilation outside of the intensive care unit: an Italian survey. Minerva Anestesiol 2011;77(3):313-322.

7. Bierer GB, Soo Hoo GW. Noninvasive ventilation for acute respiratory failure: a national survey of Veterans Affair Hospitals. Respir Care 2009;54(10):1313-1320.

8. Guarracino F, Cabrini L, Ferro B, Landoni G, Lembo R, Mucchetti $\mathrm{M}$, et al. Noninvasive ventilation practice in cardiac surgery patients: insights from a European survey. J Cardiothorac Vasc Anesth 2013; 27(5):e63-e65.

9. Burns KE, Sinuff T, Adhikari NK, Meade MO, Heels-Ansdell D, Martin CM, Cook DJ. Bilevel positive pressure ventilation for acute respiratory failure: survey of Ontario practice. Crit Care Med 2005; 33(7):1477-1483.

10. Doherty MJ, Greenstone MA. Survey of non-invasive ventilation in patients with acute exacerbations of chronic obstructive pulmonary disease in the UK. Thorax 1998;53(10):863-866.

11. Kumle B, Haisch G, Suttner SW, Piper SN, Maleck B, Boldt J. [Current status of non-invasive ventilation in German ICUs: a postal survey]. Anasthesiol Intensivmed Notfallmed Schmerzther 2003; 38(1):32-37. Article in German.

12. Crimi C, Noto A, Princi P, Esquinas A, Nava S. A European survey of non-invasive ventilation (NIV) practices. Eur Respir J 2010;36(2): 362-369.

13. Demoule A, Girou E, Richard JC, Taillé S, Brochard L. Increased use of noninvasive ventilation in French intensive care units. Intensive Care Med 2006;32(11):1747-1755.

14. Hess DR, Pang JM, Camargo CA Jr. A survey of the use of noninvasive ventilation in academic emergency departments in the United States. Respir Care 2009;54(10):1306-1312. 
15. Maheshwari V, Paioli D, Rothaar R, Hill NS. Utilization of noninvasive ventilation in acute care hospitals: a regional survey. Chest 2006;129(5):1226-1233.

16. Scala R, Windisch W, Köhnlein T, Cuvelier A, Navalesi P, Pelosi P. Targeting European Respiratory Society Group activities: a survey of the Noninvasive Ventilatory Support Group. Eur Respir Rev 2014; 23(132):258-260.

17. Scala R, Corrado A, Confalonieri M, Marchese S, Ambrosino N. Increased number and expertise of Italian respiratory high-depen- dency care units: the second national survey. Respir Care 2011; 56(8):1100-1107.

18. Plant PK, Owen JL, Parrott S, Elliott MW. Cost effectiveness of ward based non-invasive ventilation for acute exacerbations of chronic obstructive pulmonary disease: economic analysis of randomised controlled trial. BMJ 2003;326(7396):956.

19. Carlucci A, Delmastro M, Rubini F, Fracchia C, Nava S. Changes in the practice of non-invasive ventilation in treating COPD patients over 8 y. Intensive Care Med 2003;29(3):419-425. 